\title{
La reorientación afectiva de la nación en tiempos de la seguridad democrática (2002-2010) y sus efectos de verdad sobre la escuela*
}

The Affective Reorientation of the Nation in Democratic Security Times (2002-2010) and Its Real Effects on the School

A reorientação afetiva da nação em tempos de segurança democrática (2002-2010) e seus reais efeitos sobre a escola

Jefferson Jaramillo-Marín** iD orcid.org/0000-0002-0016-7631 Andres Felipe Amaya-Sierra*** iD orcid.org/0000-0003-3360-0320

Para citar este artículo: Jaramillo-Marín, J. y Amaya-Sierra, A. (2021). La reorientación afectiva de la nación en tiempos de la seguridad democrática (2002-2010) y sus efectos de verdad sobre la escuela. Revista Colombiana de Educación, 1/(81), 13-34. https://doi.org/10.17227/rce.num81-10415

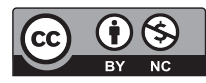

* $\quad$ Artículo de reflexión derivado de la investigación Emociones políticas, dispositivos escolares y discursos educativos en tiempos de Seguridad Democrática (2002-2010) realizada dentro del grupo de investigación Política Social y Desarrollo (Al Minciencias).

** Doctor en Investigación en Ciencias Sociales. Profesor titular de la Pontificia Universidad Javeriana. Correo: jefferson.jaramillo@javeriana.edu.co

*** Magister en Educación. Secretaría de Educación del Distrito Capital, Colombia. Correo: afamayas@ educacionbogota.edu.co 


\section{Resumen}

Este artículo de reflexión indaga cómo la seguridad democrática y la revolución educativa, en tanto programas educativos bandera del Gobierno de Álvaro Uribe Vélez (2002-2010), lograron posicionar una lectura polémica de la realidad sociopolítica del país, además de sus posibles efectos de verdad en la escuela. A partir de algunos trazos teóricos y metodológicos provenientes de la perspectiva genealógica buscamos comprender las prácticas, los saberes y los poderes en juego en la relectura de pasado reciente realizada por la seguridad democrática. Como hipótesis se sostiene que esta reorientación afectiva está vinculada a diversos dispositivos escolares e ideologemas, así como a políticas de olvido del maestro como trabajador de la cultura. La principal conclusión del artículo es que más que negación de la enseñanza de la historia, el Gobierno de la seguridad democrática buscó una instrumentalización de esta mediante la movilización de emociones políticas y la domesticación de una interpretación del pasado reciente en Colombia.

\section{Palabras clave}

memoria; experiencia emocional; educación histórica; democracia; políticas de educación

\section{Keywords}

Memory; emotional experience; educational

history; democracy; educational policies

\begin{abstract}
This reflection paper explores how the Democratic Security and the Educational Revolution, as an educational flagship program of the government of Álvaro Uribe Vélez (2002-2010), positioned a controversial reading of the social and political reality of the country, as well as its possible effects in schools. Within the framework of some theoretical and methodological features derived from a genealogical perspective we attempt to understand the practices, knowledge and powers involved in the Democratic Security's re-reading of the recent past. The hypothesis states that the affective reorientation of the nation is connected to different school devices and ideologemes, and to policies that neglect the role of teachers as culture workers. The main conclusion of the article is that rather than denying the teaching of history, the democratic security government sought its instrumentalization through the mobilization of political emotions and the taming of an interpretation of the recent past of Colombia.
\end{abstract}

\section{Resumo}

Este artigo de reflexão averigua como a segurança democrática, e a revolução educacional como programas educacionais emblemáticos do governo de Álvaro Uribe Vélez (2002-2010), conseguiram posicionar uma leitura controversa da realidade sociopolítica do país, além de seus possíveis efeitos da verdade na escola. Partindo de algumas orientações teórico-metodológicas na perspectiva genealógica, buscamos compreender as práticas, saberes e poderes em jogo na releitura do passado recente realizada pela segurança democrática.. Como hipótese, argumenta-se que essa reorientação afetiva está ligada a vários dispositivos escolares e ideologemas, bem como às políticas de esquecimento do professor como trabalhador da cultura. A principal conclusão do artigo é que, em vez de negar o ensino de história, o governo da segurança democrática buscou uma instrumentalização da mesma mobilizando emoções políticas e domesticando uma interpretação do passado recente na Colômbia.

\section{Palavras-chave}

memória; experiência emocional; educação histórica; democracia; políticas educativas 


\section{Puntos de partida y aclaraciones metodológicas}

Un tema reconocido, aunque aún por explorar con mayor profundidad en el caso colombiano, es la relación de la seguridad democrática con la circulación de una narrativa histórica que, en palabras del investigador Fabio López de la Roche (2014), ha dado lugar a una "reorientación afectiva de la nación". En este artículo de reflexión, producto de una investigación reciente en torno a la relación entre emociones políticas, dispositivos escolares y discursos educativos en tiempos de seguridad democrática (2002-2010), sostenemos que esta reorientación fue posible debido a una estrategia de difusión y consolidación de una reinterpretación del pasado de gran relevancia para determinados grupos sociales o políticos, que devino en una polémica política de memoria. ${ }^{1}$ Esta política estuvo motivada por la intencionalidad de "proyectar un cierto tipo de sociedad hacia el futuro en la perspectiva de lograr la mayor cohesión ideológica posible" (Rodríguez, 2013, p. 38).

Uno de sus correlatos discursivos —aunque no el único- fue la permanente estrategia de negación del conflicto armado en Colombia durante el Gobierno de Álvaro Uribe Vélez (2002-2010) con impactos diversos en la relectura del pasado reciente y la enseñanza de las ciencias sociales. ${ }^{2}$ Nuestro supuesto analítico es que la negación se tradujo en una obliteración inducida de las dinámicas, lógicas y saldos de lo ocurrido en las últimas décadas en el país, reduciendo el análisis de contexto a una simple pero efectiva enunciación de un enfrentamiento entre buenos y malos. Con esto último, se contribuyó al fortalecimiento, a múltiples escalas (una de ellas la pedagógica ${ }^{3}$ ), de una forma de memoria deshidratada y maniquea que impulsó esta administración.

1 Entendemos por política de memoria un conjunto de órdenes y prácticas discursivas establecidas por parte del Estado y las élites que apuntan a configurar su legitimidad sobre la gestión del pasado. Sin embargo, están abiertas siempre a la circulación y a las apropiaciones y reapropiaciones por parte de públicos diversos. Esta aproximación deriva de Salamanca y Jaramillo (2019).

2 Sobre la política de negación durante los dos periodos del Gobierno de la seguridad democrática existen diversas vetas analíticas, entre las cuales es posible mencionar Jaramillo (2014) y Atehortúa (2007).

3 Asumimos la pedagogía como "[...] un ámbito múltiple, configurado por diversas líneas de fuerza en las que se reflejan las tensiones y pugnas del contexto político, socioeconómico y cultural en el cual se inscribe, lo afecta y lo redistribuye" (Pinilla y Rodríguez, 2005, p. 168). 
En esa configuración reconocemos un papel central del dispositivo escolar. ${ }^{4}$ Se entiende este como el conjunto de prácticas y saberes impulsados y puestos en ejecución, en este caso por el Gobierno de la seguridad democrática desde el Ministerio de Educación Nacional (MEN) para lograr impactar pedagógicamente un programa político. Esta serie de prácticas y saberes están conectados a una política pública educativa, a planes de estudio, a programas de formación docente y a materiales didácticos producidos desde instancias gubernamentales en el marco de un proyecto social. Los dispositivos escolares tienen como objetivo esencial "gobernar, controlar, orientar, dar un sentido que se supone útil a los comportamientos, gestos y pensamientos de los individuos" (García Fanlo, 2011, p. 2).

Teniendo como eje rector esta categoría, debatimos en este artículo de reflexión sobre la manera en que la seguridad democrática, y la revolución educativa como programa educativo bandera del Gobierno de Álvaro Uribe Vélez, lograron posicionar una lectura polémica de la realidad social y política del país en las instituciones educativas. Preguntarnos por las sutiles formas en las que un régimen político, a través de dichos dispositivos, busca impactar en la sociedad nos llevó a asumir algunos aspectos asociados a la investigación genealógica.

Los trazos que privilegiamos para detonar la indagación fueron: 1) el análisis de prácticas discursivas, es decir, de aquellos "conjuntos de enunciados que provienen de un mismo sistema de formación, que se articulan históricamente en saberes y que se validan desde un régimen reglado sostenido por relaciones de poder" (Martínez, 2010, p. 86); 2) el reconocimiento del "[...] análisis histórico en la producción de discursos y los modos como funcionan en tanto que detonadores y sustentadores de relaciones de poder capaces de producir subjetividades" (Martínez, 2014, p. 74); y 3) la necesidad de asumir un "discurso histórico que se cuestiona a sí mismo, como una contra historia que dice lo no dicho por la historia oficial" (Martínez, 201, p.76). ${ }^{5}$

4 En el camino de indagación más amplio frente a la noción de dispositivo seguimos a Agamben (2011), para quien este es un conjunto de prácticas y mecanismos (discursivos y no discursivos, jurídicos, técnicos y militares) que tienen por objetivo producir un efecto más o menos inmediato en la sociedad. También a Martínez (2013), para quien el dispositivo configura formas de "ser, hacer y de conocer del sujeto", triada que constituye uno de los rasgos fundamentales para la construcción de subjetividades en el marco de una red de relaciones.

5 En la investigación general que da origen a este artículo (Amaya, 2019), estos trazos se documentaron con información proveniente de tres fuentes: 1) las entidades oficiales, principalmente del Ministerio de Educación Nacional, durante los ocho años del Gobierno de la seguridad democrática (decretos, directivas ministeriales, lineamientos y estándares curriculares), especialmente la documentación producida sobre la educación básica y media; 2) el archivo de prensa, en un periodo de ocho años, que se adelantó con base en la digitalización de estos medios de información que lleva a cabo, desde hace algunos años, el Centro de Investigación y Educación Popular (Cinep); 3) el trabajo con entrevistas que permitió detonar con algunas personas destacadas por 
Estos criterios, además, orientaron la estructura del texto. En un primer momento se indaga por la política de memoria que impulsó el Gobierno de Álvaro Uribe Vélez, y su impacto en la forma de asumir nuestro pasado reciente. En un segundo momento se muestra cómo esta política posibilitó elaborar algunos elementos comprehensivos en relación con la relectura del pasado reciente y la enseñanza de las ciencias sociales, produciendo algunos efectos de verdad. Se examina también cómo el regreso de las competencias ciudadanas en los currículos escolares fue parte de los dispositivos escolares movilizados para estos fines. Se enuncia, además, el olvido y el silenciamiento de la figura del maestro como actor político, como trabajador de la cultura, bajo la extendida y naturalizada idea del profesor como "administrador de un servicio".

\section{La reorientación afectiva de la nación como política de memoria en Colombia}

La reorientación afectiva de la nación operó, desde nuestra óptica, a través de cinco prácticas discursivas validadas por el régimen de la seguridad democrática, ${ }^{6}$ con efectos prolongados en el tiempo, a saber: 1) la no existencia de conflicto; 2) la idea de un enemigo público en común; 3) la reiteración de que el relato histórico nacional ha sido ideologizado por la izquierda; 4) el desconocimiento público de la responsabilidad histórica del Estado como perpetrador; y 5) la ratificación permanente del heroísmo militar. Examinemos cada una de ellas.

En el caso de la no existencia de conflicto, dos hitos discursivos son sugestivos al respecto. El primero ocurrió en el 2005 con la publicación del libro Sofismas del terrorismo en Colombia, escrito por el hoy senador del Centro Democrático José Obdulio Gaviria, quien, para la fecha de su publicación, oficiaba como uno de los principales asesores del entonces presidente Álvaro Uribe Vélez. El título del libro sugiere de antemano la postura analítica e histórica que defendió este régimen presidencial en Colombia entre 2002 y 2010: la inexistencia del conflicto armado en Colombia y, con ello, la justificación del "tratamiento especial", y básicamente militar y planificado para enfrentar la "amenaza terrorista".

su trayectoria en el campo de la educación y la pedagogía, perspectivas críticas sobre lo ocurrido en este periodo. Estas distintas fuentes fueron analizadas con un recurso técnico para el análisis como es el del discurso social, tomando libremente aportes provenientes de Teun A. van Dijk (1999), Sara Ahmed (2015) y Marc Angenot (2010).

6 Sobre la seguridad como técnica normalizada durante el Gobierno de Uribe Vélez se recomienda Muñoz-Onofre (2015). 
En este trabajo, el senador ambicionó "demostrar — con objetividad, sin caer en el macartismo ni en la seducción y el embrujo del sofisma violento- que en el terreno del verbo se dan los más trascendentales combates de la confrontación de los violentos contra el Estado colombiano" (Gaviria, 2005, p. 22). Desde esta perspectiva, conceptos como conflicto interno armado, guerra civil, acuerdo humanitario han sido parte del "embrujo" producido, por el uso sistemático de un lenguaje "funcional a las organizaciones terroristas" que tienen presencia en el territorio colombiano. Esas expresiones, propias de las organizaciones de derechos humanos y profesores universitarios "[...] obstruyeron o neutralizaron, consciente o inconscientemente, la acción estatal" (Gaviria, 2005, p. 22).

Un segundo hito discursivo está presente en las declaraciones dadas en el marco de una entrevista radial en noviembre del 2017 por la Representante a la Cámara por Bogotá María Fernanda Cabal, quien afirmó que: "la masacre de las bananeras es un mito histórico que trae siempre la narrativa comunista". Desde la óptica de la mencionada representante:

La confrontación si existió. Lo que se convirtió en un mito es el hecho de que la masacre la cometiera el Ejército contra unos trabajadores que estaban desarmados. Eso es mentira, los trabajadores fueron armados por la Internacional Socialista y fueron ellos los que atacaron a la fuerza pública. (Casañas, 2017).

Además de estas palabras, María Fernanda Cabal señaló al nobel de literatura colombiano como uno de los principales exponentes de esta "narrativa comunista":

García Márquez se inventó que en las bananeras hubo 3 mil muertos. Usted hoy en día no consigue ese número de trabajadores. Él tiene la responsabilidad de distorsionar la historia inventándose esa cifra de trabajadores asesinados. Él era una figura literaria y como él utilizaba el realismo mágico, uno no sabe si lo hacía como parte de su creatividad o como parte de su maldad por ser militante del partido comunista. Hay gente que sigue repitiendo eso como un hecho histórico. (Casañas, 2017, énfasis añadido).

Ni las afirmaciones de María Fernanda Cabal ni las de José Obdulio Gaviria pueden ser comprendidas como expresiones aisladas de dos personalidades excéntricas del escenario político colombiano. Sus particulares versiones sobre la historia de Colombia están inscritas dentro del conjunto de una política de la memoria impulsada durante la administración de Uribe Vélez con el fin de crear unas tramas narrativas revisionistas conformes a sus intereses como sectores de élite gobernante. 
Respecto a la idea de un enemigo público en común para el país, es importante considerar que el escalamiento del conflicto armado y político durante los dos periodos presidenciales de Uribe Vélez condujo a que el Gobierno comprendiera que "su guerra" debía librarse, además del plano militar, en la construcción de un enemigo en común en el que recayera toda la culpabilidad de las problemáticas del país. Esta situación se tradujo eficazmente en la movilización de un conjunto de emociones públicas en contra de la violencia ejercida por los grupos guerrilleros, particularmente las FARC, siendo célebre la marcha del 4 de febrero del 2008 convocada bajo el lema "Un millón de voces contra las FARC", día en el que el país vivió una intensa jornada de protesta contra esta organización subversiva. Si bien la construcción de un enemigo público en común ha sido a lo largo de la historia nacional uno de los dispositivos más utilizados para opacar y exterminar al opositor, durante el periodo de la seguridad democrática se usó específicamente para el fortalecimiento del principio programático y político de negación del conflicto armado.

Aparte de la construcción de este chivo expiatorio, la reorientación afectiva contó con otro mecanismo que, desde nuestro análisis, logró configurar un "nuevo mapa afectivo de la política" y fue la presentación reiterada, ante la opinión pública, de la idea de que la historia, y en general el conjunto de disciplinas de las Ciencias Sociales en el país, han estado altamente ideologizadas. La negación del conflicto armado, en este estado de cosas, requería de una nueva forma de elaborar y presentar el análisis histórico y político, como de hecho se presentó años más tarde en una versión de la seguridad democrática consignada en un texto escolar de la Editorial Santillana para alumnos de quinto grado (Figura 1). Lo significativo aquí no es solo que se tratara de generar una nueva versión de la historia reciente, sino de exhibir a la política de seguridad democrática como algo necesario e inevitable para el país, soportado por estudios técnicos que mostraban la viabilidad y la pertinencia de este modelo para el "rencauzamiento institucional del país".

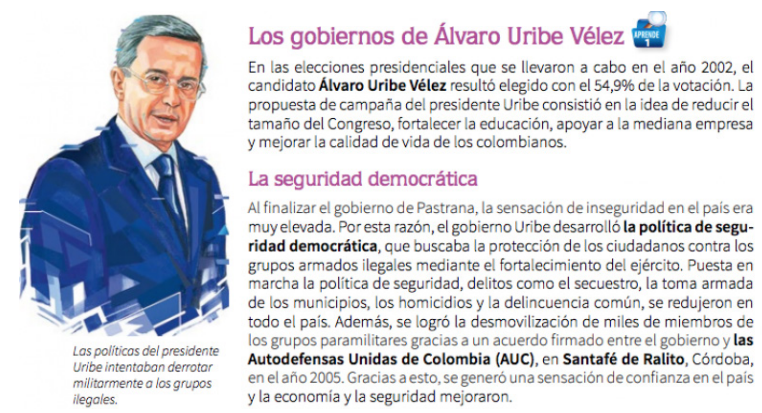

Figura 1. La versión gobiernista de la Administración de Uribe en el texto escolar. Fuente: https://www.rcnradio.com/internacional/respuesta-de-la-editorial-santillana-polemica-por-texto-educativo 
La trama narrativa de la seguridad encontró eco y respaldo en investigadores sociales, en algunos casos por la novedad de una promesa política de cambio, en otros por el convencimiento absoluto de las cualidades de esta forma de gobierno. Ambas lecturas, pese a sus diferencias, se instalaron en la idea de que la existencia de un Estado central fuerte estaba siendo debilitada por el accionar violento de grupos armados que amenazaban la viabilidad de Colombia como Estado-Nación. Precisamente, a solo un año de la llegada de Álvaro Uribe a la Casa de Nariño, el destacado sociólogo Eduardo Pizarro Leongómez señalaba que

Gracias a este cambio [hacia la Seguridad Democrática], la balanza estratégica en el conflicto armado interno comienza a favorecer de manera creciente al Estado colombiano, lo cual permite vislumbrar una luz al final del túnel, es decir, el final del conflicto crónico interno. Pero, en buena medida, esto va a depender de la sostenibilidad del proyecto de "seguridad democrática" y del apoyo de la comunidad internacional. A su turno, esto solo es viable si el Gobierno no cae en excesos autoritarios y mantiene un respeto irrestricto a los derechos humanos $y$, ante todo, si el horizonte estratégico del fortalecimiento institucional es abrir un camino viable para una solución final negociada al conflicto armado interno. (Pizarro Leongómez, 2003, p. 17).

La otra práctica agenciada fue la del desconocimiento de la responsabilidad histórica del Estado como perpetrador. Frente a la misma sorprenden, por ejemplo, las pocas menciones en medios o en la academia sobre las medidas de excepción tomadas por esta administración una vez instalado en el poder, entre otras: la declaratoria del estado de emergencia, las zonas especiales o las detenciones masivas. ${ }^{7}$ A la omisión, también se sumaron las declaraciones panegíricas sobre este proyecto político, como queda también evidenciado en el trazo del reputado colombianólogo inglés Malcolm Deas:

Creo que Uribe era un presidente que necesitaba Colombia. Después de él hay un antes y un después [...] Pero, además, sus críticos se equivocan cuando dicen que solo pensaba en una solución militar. Él intentó abrir con las Farc un diálogo y no es cierto que haya estado en contra de la paz. Uribe lo que ha dicho es que está en contra de una paz con impunidad. (Duzán, 2014).

7 Dos ejemplos de estas capturas fueron la derivada de la Operación Libertad en Quinchía, Risaralda el 28 de septiembre del 2003 y la realizada el 22 de noviembre del 2002 en Calamar, Guaviare. En la primera se realizó una captura ilegal de más de 110 personas acusadas de rebelión y de ser auxiliadoras del frente Oscar William Calvo, una disidencia del grupo armado EPL. En la segunda, se acusó sin pruebas a varias personas de la Administración pública de pertenecer al Frente $1 .^{\circ}$ Armando Ríos de las Farc. En ambas operaciones participaron la Policía, el Ejército y la Fiscalía General de la Nación y las acusaciones se hicieron con base en declaraciones de testigos anónimos. 
Esta forma de tramitar la narrativa histórica del país contó con el apoyo de dos de los canales privados de información que operan en Colombia: RCN y Caracol, quienes mantuvieron una línea editorial cercana a esta particular forma de agenciar el pasado por parte del Gobierno. Su manera de narrar la amenaza terrorista, como empezó a ser denominado política y mediáticamente el conflicto armado colombiano, siguió los derroteros que en esta materia señalaba esta administración, logrando considerar públicamente a las FARC como "el único enemigo del país y, por supuesto, el único responsable de la crisis del país" (López de la Roche, 2014, p. 35).

El golpe de opinión que representó el conocimiento de los "falsos positivos" desembocó en otra importante movilización de emociones a favor de las Fuerzas Militares, responsables directas, en muchos casos, de las ejecuciones extrajudiciales, lo que se tradujo en visibles campañas mediáticas que tuvieron como eslogan central "Los héroes en Colombia sí existen". El deliberado trabajo por reforzar el heroísmo militar buscó elevar, mediante el marketing, el apoyo del grueso de la sociedad colombiana a las instituciones castrenses (Fattal, 2018).

A la par que el país conocía los horrores de las ejecuciones extrajudiciales, particularmente los casos de los jóvenes de barrios marginales de Bogotá y su área metropolitana, fue común la circulación en los medios de información de spots (comerciales) que desempeñaron un papel decisivo la incorporación de la noción de héroe, aquel ser capaz de entregar su vida, si fuese necesario, por la causa de la nación. Así, la frase "Yo a usted no lo conozco, pero estoy dispuesto a dar la vida por usted" (figura 2) tuvo una fuerte resonancia. La vida, en este caso, es puesta como el último recurso, el valor supremo para demostrar las capacidades éticas y el compromiso inquebrantable de los miles de hombres que conforman las tropas colombianas.

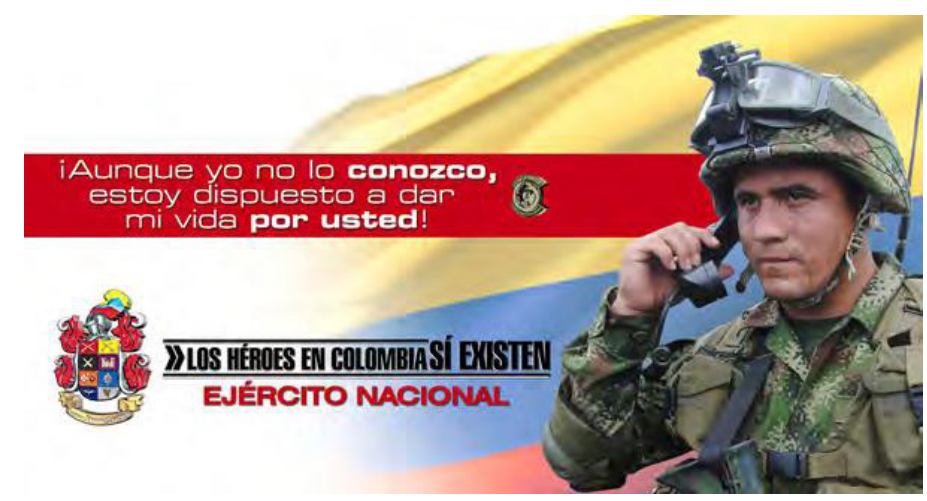

Figura 2. La movilización de emociones en la defensa del honor patrio. Fuente: https://www.flickr.com/photos/ejercito-nacional/9424837789 y http://oficialejercito. blogspot.com/2013/ 
Dentro de las paradojas de este tipo de estrategias está precisamente que, aunque la vida sea presentada como fin y como medio, la muerte de insurgentes no es enunciada como crimen, sino como "baja". Esta lógica binaria de la guerra en el país llevó a que la muerte fuera celebrada cuando se presentaban los partes de guerra sobre las contundentes cifras de bajas al enemigo y su aparente e inminente derrota, mientras que era lamentada cuando las víctimas eran hombres de los destacamentos militares.

Estas prácticas discursivas, que identificamos como parte del engranaje de la reorientación afectiva de la nación no pueden ser comprendidas sin relación con la Ley 975 de 2005 (ley de justicia y paz). Aunque no es tema de interés aquí, vale resaltar que en este marco normativo el Estado colombiano perfiló sus planteamientos en torno a la construcción de una forma de recordar el pasado, reparar a los afectados y responsabilizar a los perpetradores en un manto de sombras y luces (Jaramillo, 2014). En ese encuadre normativo, la paz del Gobierno de Uribe Vélez fue presentada como revitalizadora de la seguridad y la democracia en el territorio nacional y como proclive a una salida negociada a la guerra, sin embargo, esta tuvo el difuso y ambiguo rostro de la pax romana: la de la "mano firme y el corazón grande".

\section{La reorientación afectiva del país y sus efectos de verdad sobre la escuela y la enseñanza de las ciencias sociales}

En el 2012 Álvaro Uribe Vélez, en calidad de expresidente, visitó varios colegios de carácter privado en Bogotá y Medellín. En estas instituciones, ofreció a estudiantes, profesores y padres de familia conferencias en las que conversó sobre los logros de su Administración (2002-2010), disertó sobre liderazgo y emprendimiento y expuso su interpretación de la historia reciente del país. La presencia del exmandatario — de tan importante peso en el escenario político colombiano durante las dos últimas décadas - en instituciones educativas, puede ser comprendida como ese proceso de reactualización histórica adelantado por los sectores gobernantes, en su afán por conquistar la escuela y, con ello, de su importante papel en la construcción de imaginarios de nación. En las conferencias referenciadas, Uribe Vélez exponía a los escolares temas relacionados con su gestión como expresidente y como exgobernador, y reflexionaba sobre sus ideas y perspectivas acerca del acontecer político y social del país. Entre otras opiniones, el mencionado líder político sostenía que "Nuestra gobernación de Antioquia fue eficaz" "Desmontamos el paramilitarismo y la guerrilla, redujimos sustancialmente el narcotráfico. Entonces me vinieron miles de acusaciones, pero esas a mí me rebotan 
porque cumplí con el deber" "Cuando ustedes no habían nacido, yo era gobernador". "Era una voz aislada en el tema de seguridad" (Restrepo, 2012, párr. 21).

En relación con lo anterior es posible pensar que, en los programas de gobierno de Álvaro Uribe Vélez, si bien estaba en juego una particular política de olvido frente a nuestro pasado reciente, lo que se presentaba a la opinión pública era un conjunto de estrategias de eficiencia que abogaban por un carácter técnico de las decisiones para legitimar la optimización de los recursos propias de una revolución educativa que pretendía mayores logros en cobertura y calidad (Rodríguez, 2016). Sin embargo, es innegable que los lineamientos gubernamentales eran acciones sociales con intencionalidades claramente políticas en la educación.

Desde esta óptica es posible entrever que la revolución educativa buscó difundir ciertos ideologemas ${ }^{8}$ que no pretendieron entrar en choque frontal con la "enseñanza de la historia" y las interesantes apuestas que se registran en este campo. Por el contrario, se buscó su domesticación y, cuando no era posible, su invisibilización y estigmatización. ${ }^{9}$ De hecho, durante este periodo no aparecen visibles una serie de iniciativas pedagógicas y políticas que conciben otras formas de asumir lo educativo. ${ }^{10}$

Al señalar que la enseñanza de la historia quiso ser domesticada, lo hacemos con precaución de método. La amplia y prolífica producción sobre el tema demuestra que, a nivel disciplinar/historiográfico y pedagógico, ha existido un ingente esfuerzo por posicionar la enseñanza de la historia en las instituciones educativas como un área central en la formación de los estudiantes colombianos, lo que podría sugerir al lector que la enseñanza-aprendizaje de este saber ocupa un lugar central en el debate educativo colombiano. Sin embargo, un acercamiento in situ, una lectura desde nuestra experiencia como educadores nos lleva a realizar esta cautela, no con el ánimo de desvalorar todo este acumulado investigativo, sino con el fin de generar otros cuestionamientos que giran, primordialmente, en torno al pronunciado distanciamiento entre este copioso trabajo académico y las prácticas pedagógicas escolares.

8 Con esta categoría nos referimos a "unidades significantes dotadas de aceptabilidad difusa en una doxa dada" (Angenot, 2010, p. 25).

9 Uno de los casos más sonados es la persecución al profesor universitario Miguel Ángel Beltrán Villegas en mayo del 2009, cuando éste adelantaba sus estudios posdoctorales en México. Después de años de una intensa defensa judicial, el profesor Beltrán logró su libertad y, hoy en día, volvió a vincularse al Departamento de Sociología de la Universidad Nacional. A nivel de Educación Básica, otro caso de falso positivo judicial fue el del profesor William Javier Díaz, adscrito a la Secretaría de Educación de Bogotá.

10 Aclaramos que los silencios también pueden ser estratégicos, cómplices, normalizadores o negadores del orden social vigente. 
A lo anterior se añade otro elemento importante y es la discusión sobre los efectos de verdad y las resistencias sobre la enseñanza de las ciencias sociales con la promulgación del Decreto 1002 de 1984. Si bien con este se estableció que el área de historia quedara integrada en lo que genéricamente se denominó en el país Ciencias Sociales, situación que implicó el adelgazamiento del espacio académico destinado a la reflexión del pasado, tanto universal como local, también es cierto que no fueron pocas las reflexiones historiográficas, pedagógicas y didácticas que revelaron la preocupación genuina de historiadores y educadores por mantener la enseñanza de esta área en las instituciones de educación básica y media del país.

\section{"Ciudadanos competentes" en el marco del fin del conflicto armado en Colombia: el olvido de las razones políticas de la guerra}

A las excesivas exigencias gubernamentales para el área de Ciencias Sociales, ${ }^{11}$ la revolución educativa sumó la cátedra de Competencias Ciudadanas al ya atiborrado currículo escolar. En el 2004 se publicó el texto Formar para la ciudadanía... isí es posible! Lo que necesitamos saber y saber hacer (MEN, 2004), un extenso documento en el que se exponen los Estándares Básicos de Competencias Ciudadanas. Partiendo de un diagnóstico producto de la aplicación de una prueba estandarizada, los técnicos señalan la importancia de la formación en ciudadanía desde los primeros años de la Educación Básica, en los que se garantice un mínimo de actitudes, aptitudes y saberes indispensables, según esta política, para la vida social. Según la doxa de sentido que se va perfilando, los colombianos somos "ciudadanos a medias" (figura 4).

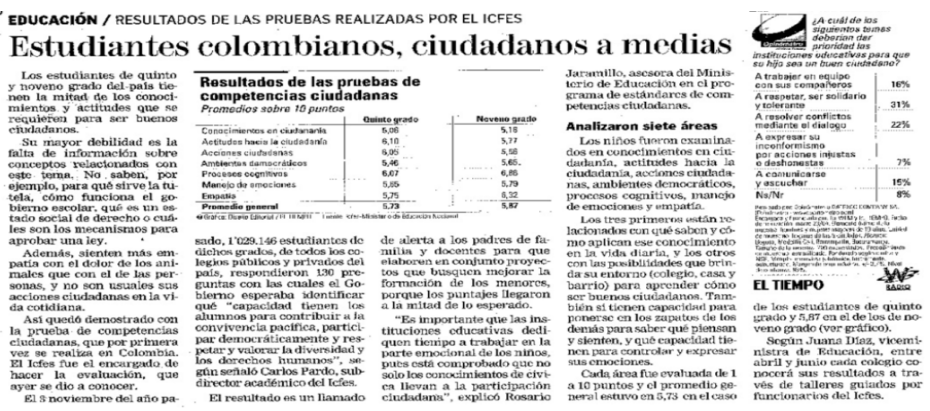

Figura 3. Ciudadanías a medias

Fuente: "Estudiantes colombianos, ciudadanos a medias" (2004,27 de marzo). El Tiempo, pp. 1-17

11 A parte de la historia y la geografía, los docentes de Ciencias Sociales deben dar cuenta de cátedras de Afrocolombianidad, Religión, Ética y Valores, Paz, entre otras tantas. 
Para los técnicos de la educación las competencias ciudadanas se van a convertir en un instrumento sine qua non para que los escolares adquieran hábitos democráticos desde las instituciones educativas. Alcanzar este cometido implica trabajar el conjunto de "conocimientos y de habilidades cognitivas, emocionales y comunicativas que, articulados entre sí, hacen posible que el ciudadano actúe de manera constructiva en la sociedad democrática" (MEN, 2004, p. 8). Como en otras tantas iniciativas, se asume que la experticia está por fuera del aula y los educadores, casi siempre, son receptores pasivos de estas políticas, reforzando con ello la desprofesionalización de la actividad docente que tiene carrera en nuestro país.

Los Estándares en Competencias Ciudadanas se organizaron en grupos y tipos. En el primer caso, se discriminaron en tres grupos: Convivencia y paz, Participación y responsabilidad democrática y, por último, Pluralidad, identidad y valoración de las diferencias. En relación con los tipos, se disgregaron en competencias cognitivas, emocionales, comunicativas e integradoras. Con base en esta taxonomía, el documento propuso una serie de estándares agrupados para los distintos grados que componen la organización del actual sistema educativo colombiano. Esta serie de estándares, así como el marco de la formación ciudadana propuesto, tendrán como eje central "el respeto, la defensa y la promoción de los derechos humanos". En sus palabras:

Las competencias ciudadanas se enmarcan en la perspectiva de derechos y brindan herramientas básicas para que cada persona pueda respetar, defender y promover los derechos fundamentales, relacionándolos con las situaciones de la vida cotidiana en las que estos pueden ser vulnerados, tanto por las propias acciones, como por las acciones de otros. En esas situaciones, las competencias ciudadanas representan las habilidades y los conocimientos necesarios para construir convivencia, participar democráticamente y valorar el pluralismo. (MEN, 2004, p. 6)

Sin embargo, en el documento poco o nada se dice de la situación en materia de derechos humanos en Colombia durante los primeros meses de la Administración de la seguridad democrática. Ante este silencio, es necesario recordar cómo, durante el primer año de este Gobierno

[...] el Banco de Datos [del Cinep] registró las siguientes cifras: 4.351 personas fueron víctimas de violaciones a los derechos humanos, de acuerdo con las siguientes modalidades: amenazas: 573; desapariciones forzadas: 160; detenciones arbitrarias: 2.546; ejecuciones extrajudiciales: 792; torturas: 144; y en menor número: víctimas de atentados, heridos y de violencia sexual. En cuanto a los responsables de estas violaciones se encuentran: los grupos paramilitares aparecen como supuestos responsables de 1.510 casos; Fuerzas Militares (Armada, Ejército, Fuerza Aérea) de 1.246; la Policía de 327 y otros organismos de Seguridad del Estado (DAS, CTI, Gaula, Inpec) de 1.268. (Plataforma Colombiana de Derechos Humanos, 2003, p. 115) 
En ese marco, ninguna mención existe de las múltiples formas de violencia que se ejercieron, y se ejercen, contra la Escuela en distintas zonas de la geografía nacional en las que los actores armados convirtieron sus instalaciones en lugares fundamentales dentro de la estrategia militar con la que operaban en el curso del conflicto armado. Igualmente, se invisibilizó la violencia contra los maestros, específicamente el asesinato y el desplazamiento (gráfica 1).

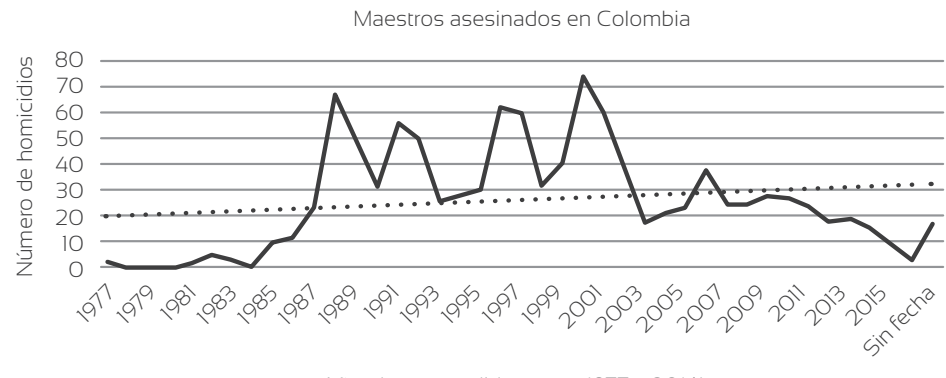

Años (comprendidos entre 1977 y 2016)

Gráfica 1. Maestros asesinados en Colombia 1977-2016.

Fuente: elaboración propia a partir de los datos de Fecode

Ahora bien, el adelgazamiento sistemático del concepto de conflicto armado y de sus saldos funestos no es, como podría pensarse, un asunto de poca monta para las Ciencias Sociales. Como bien lo señala Rodrigo Uprimny (2005)

[...] el uso del lenguaje no es inocente, ya que tiene efectos sobre la realidad, en la medida en que define la manera como los ciudadanos perciben y comprenden un determinado problema [...] cualquier concepto que se seleccione estaría definiendo la naturaleza del conflicto y condicionado así la gama de posibilidades para enfrentar su solución. (Uprimny Yepes, 2005)

Al negar el conflicto armado, este gobierno también condicionó el ejercicio ciudadano a los estrechos márgenes de su análisis sobre la realidad nacional. En estos encuadres discursivos, la protesta social contra las políticas de Gobierno fue estigmatizada, vinculándola a la estrategia desplegada por la insurgencia y justificando, de esta manera, el uso excesivo de la fuerza en el marco de estas movilizaciones, amparado en su propuesta de la recuperación del monopolio del uso legítimo de la fuerza, punto neurálgico de la política de seguridad democrática.

Las Competencias Ciudadanas se inscriben como una más de las estrategias para incrustar el ejercicio de la ciudadanía al marco normativo del Estado, desconociendo las dinámicas de las luchas históricas de los 
movimientos sociales en Colombia, quienes con sus diversos repertorios de acción colectiva han posibilitado el logro de conquistas para diferentes sectores. En este sentido, los derechos sociales consagrados por la legislación nacional son presentados como prebendas por parte del Estado a sus ciudadanos y no como resultado de la energía de movilización de muchos sectores sociales del país.

Al negar el conflicto armado, igualmente, se instaura una lectura de la historia nacional en la que las apuestas de construcción de sociedad diferentes son estigmatizadas y silenciadas. En este andamiaje conceptual, los proyectos políticos que movilizan las organizaciones sociales y políticas a lo largo de las últimas décadas serán asociados a formas de violencia extrema con lo que, además, se justificó la acción criminal contra estas.

Las violencias que sacuden al país, y a la escuela, se reducen en el análisis a la incapacidad de los colombianos para tramitar sus diferencias, encubriendo la injusticia social y la precariedad del Estado para atender las demandas más sentidas de la población. No se hace mención, por supuesto, al sectarismo político que movilizó la clase gobernante en Colombia y que se tradujo en persecuciones a la oposición, violación sistemática a los derechos humanos y la desaparición forzada, prácticas que, como lo demuestra el Cinep, ${ }^{12}$ no son circunstanciales, sino que responden a una política de Estado. Bajo el parteaguas de las Competencias Ciudadanas se fue generando el ideologema, tan difundido en nuestro país, de la violencia como manifestación pasional de los colombianos, la cual habría que administrar, regular y controlar. Nos olvidamos, entonces, de las posibles causas que la explicarían.

Con este particular tratamiento de la historia reciente del país se ha posibilitado que la mayoría de las víctimas del conflicto desaparezcan. Así, "las únicas víctimas con espacio mediático para sus reclamaciones [durante la Seguridad Democrática] son las del secuestro" (Rodríguez y Moncada, 2009, p. 11) principalmente las de las organizaciones subversivas, reforzando la política de memoria oficial tendiente a

[...] legitimar el gasto militar y la prolongación de la misma política de seguridad que le sirve de soporte, mientras la militarización naturalizada de la vida pública continúa deslegitimando la protesta social y la oposición política, encubriendo los crímenes de Estado, y desconociendo la existencia de las víctimas y sus demandas. (Rodríguez y Moncada, 2009, p. 12)

12 Particularmente en el Banco de datos de Derechos Humanos y Violencia política, en el que se "recauda, sistematiza y difunde información sobre las violaciones más graves a los derechos humanos fundamentales, así como sobre infracciones al Derecho Internacional Humanitario". Esta sistematización es presentada en la revista semestral Noche y Niebla, la cual puede ser consultada a través de la página web del Cinep. Véase: https:// www.cinep.org.co/Home2/temas/derechos-humanos/3-1-bancodatosddhh.html 


\section{¿Olvido y silenciamiento del docente como trabajador de la cultura?}

Al retorno de la cátedra de Ciudadanía se sumaron una serie de dispositivos que buscaron opacar las lecturas de la educación como un campo en permanente tensión. La educación, en este estado de cosas, debía responder a criterios técnicos: costo/beneficio, tasa de retorno, entre otros. De esta forma, el lenguaje empresarial iba enquistándose en los debates públicos sobre la temática y las prácticas pedagógicas de los educadores colombianos.

Al inicio del segundo periodo presidencial, Cecilia María Vélez firmó la Resolución 4434 del 2006 en el que el MEN establecía "las condiciones y mecanismos para la validación de los modelos de gestión de calidad de los establecimientos de educación preescolar, básica y media". Con base en las orientaciones técnicas emanadas de las normas ISO 9000: 2000, las instituciones escolares requerían ante este ministerio la "solicitud de validación de un modelo de reconocimiento de gestión de la calidad" que, de cumplir con los criterios establecidos según la legislación vigente, era otorgada o rechazada. ${ }^{13}$

A través de este dispositivo escolar, el MEN introdujo formalmente la lógica empresarial que, hizo carrera en nuestro país desde hace algunos años y condujo a la naturalización de este tipo de políticas que han posibilitado el abandono progresivo de una práctica educativa que ya no asume la educación como un derecho fundamental para la sociedad colombiana sino que, por el contrario, la asimila a un servicio que "tiene orientación al cliente", como lo señala la normatividad señalada. ${ }^{14}$

De esta manera se transitó de la idea del maestro como trabajador de la cultura al educador -administrador. La primera había sido agitada por el Movimiento Pedagógico en nuestro país, pero fue perdiendo el ímpetu con el que se posicionó décadas atrás, hasta que se consolidó la "política de olvido y de silencio" del maestro como agente importante para el cambio social.

13 La resolución del MEN establece una serie de "evidencias de la integración de conceptos de administración y aseguramiento de la calidad" que, a su vez, están conformadas por unos conceptos que deben acreditar evidencias y referencias documentales.

14 Para un análisis de estos procesos de calidad y gestión empresarial en la Universidad véase Santana (2020): “Una práctica pedagógica orientada a los procesos de calidad y gestión empresarial, como lo promueven los discursos macropolíticos en Colombia, posicionó el ideologema de un educador-administrador, limitando la praxis de los educadores y sus apuestas al registro de formatos y evidencias, requisitos obligatorios para acceder a la certificación de calidad que otorga el Ministerio, así como Icontec". 
Orientados por estos derroteros, en Colombia se arraigó el discurso de una educación en función de la calidad, la cobertura y la administración. En este régimen de verdad incuestionable, como es presentada la economía de mercado, se cristalizaron iniciativas como Empresarios por la Educación ${ }^{15}$ que, desde el 2002, ocupa un importante lugar dentro del sector educativo del país y que sitúa la política pública en esta materia en concordancia con los intereses más "genuinos" del empresariado colombiano.

La puesta en movimiento de estas doxas buscó movilizar emociones favorables a la educación como mercancía. Así, en la opinión pública fue ganando fuerza la idea de una superioridad intrínseca de la educación privada sobre la educación estatal evidenciada, entre otras cosas, en los resultados de las pruebas estandarizadas, así como en las clasificaciones periódicas que, de un tiempo para acá, circulan a través de diferentes medios (figura 5). Esta presumida superioridad recuerda las apreciaciones del destacado sociólogo estadounidense Robert K. Merton cuando habla de la profecía que se cumple a símisma, "una definición falsa de la situación que suscita una conducta nueva, la cual convierte en verdadero el concepto originalmente falso" (Merton, 2002, p. 506).
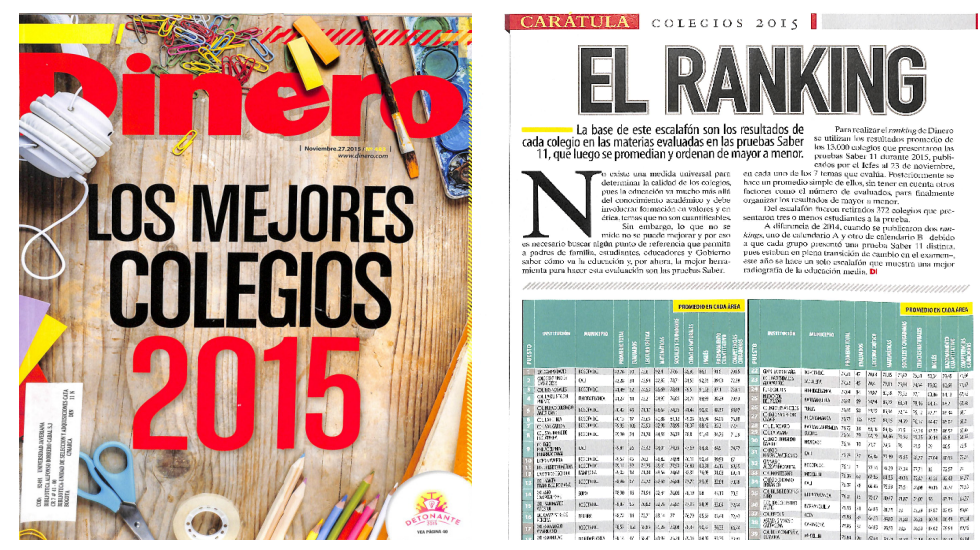

Figura 4: La base de la calidad.

Fuente: Portada Revista Dinero (noviembre del 2015)

15 La Fundación Empresarios por la Educación (FE*E) nació en el 2002, siguiendo las orientaciones del Latin American Basic Education Summit, evento realizado en Miami, Estados Unidos, en el2001 y que invitó a los empresarios a invertir más en educación. Esta organización fue promovida en Colombia por el empresario Nicanor Restrepo, quien presidiera el Grupo Empresarial Antioqueño, uno de los conglomerados empresariales más importantes del país. Véase http://fundacionexe.org.co/home/quienes-somos/ 


\section{Consideraciones finales: contradicciones y puntos de escape a la reorientación afectiva de la nación}

A la par de la promulgación de los Estándares en Competencias Ciudadanas, en este periodo entraron en vigor los Estándares Curriculares en Ciencias Sociales (2004), que se inscriben en los planteamientos trazados por los Lineamientos Curriculares en esta área promulgados en el 2002, que organizan la enseñanza de las Ciencias Sociales en ocho ejes fundamentales. Los estándares del área suponen un acercamiento al conocimiento científico social a través de tres relaciones básicas: con la historia y la cultura, con el espacio y el ambiente y con la ética y la política.

La promulgación de estos lineamientos sugiere la idea de que la política educativa no está exenta de contradicciones y de puntos de fuga. Mientras que las competencias ciudadanas atribuyen los conflictos a la "emocionalidad mal manejada de los colombianos", los estándares básicos de competencias en Ciencias Sociales abren la posibilidad de pensar las conflictividades sociales en el marco de procesos históricos, así como sus relaciones con la espacialidad y las posiciones ético-políticas que subyacen en la acción colectiva de los grupos humanos. Es decir, las competencias permitieron crear algunas zonas de quiebre a la estandarización $y$, de esta manera, la posibilidad de repensar la enseñanza de la historia reciente en clave de apuestas de sentido divergentes a las señaladas por las competencias ciudadanas.

No podríamos señalar, pese a esta expectativa abierta por los estándares en el área, de que esta situación sea el común denominador en la enseñanza de la historia reciente en Colombia. Si bien existe un importante número de iniciativas de maestros, y de redes que se han conformado alrededor de este asunto, "la inclusión de este tipo de temáticas es aún tangencial en los currículos escolares" (Amaya y Torres, 2015, p. 154), lo que nos inquieta es el marcado peso que aún tiene la enseñanza de las Ciencias Sociales, y particularmente la historia, de carácter nemotécnico y eurocéntrico en las instituciones educativas.

A diferencia de experiencias relacionadas con la educación informal y popular, en donde por sus características se ha posibilitado el agenciamiento de otros procesos de enseñanza-aprendizaje $y$, con ello, la incorporación de otras perspectivas históricas, la educación formal colombiana sigue privilegiando la enseñanza de la historia desde un abordaje cronológico, en el que los procesos históricos se asocian a la enumeración de imperios, fechas y efemérides.

La degradada y prolongada existencia del conflicto armado, político y social, así como las inequidades sociales y de género, las consecuencias sobre los territorios en el marco de la confrontación, las víctimas y sus 
demandas, entre otras tantas temáticas relevantes para comprender nuestro actual panorama sociopolítico, no se han convertido en contenidos centrales en la enseñanza de las ciencias sociales en el país. Este estado de cosas nos lleva a generar una conclusión inicial y es que más que negación de la enseñanza de la historia, en los dos periodos del Gobierno de la seguridad democrática se buscó una instrumentalización de esta a través de la movilización de unas emociones políticas y una domesticación de una interpretación sobre el pasado reciente.

Insistimos en la distancia que se sigue registrando entre la producción académica universitaria y los saberes históricos que circulan en las instituciones que reproducen un conjunto de información que parece no cambiar en el tiempo y en el espacio. La enseñanza de la historia, así comprendida, sirve de base para asimilar el pasado y presente del país al relato unilateral que se ha venido emprendiendo en el contexto de una política de memoria, de un deber de memoria impulsado por el Estado, y que perfila ideologemas como del maestro-administrador, o en el que la violencia del país es vista como un asunto de manejo de las emocionalidades, de la crisis del sistema educativo como responsabilidad de los educadores y su poco compromiso con la gestión y la calidad

Frente a los naturalizados ideologemas que puso en circulación el gobierno de la seguridad democrática, abogamos por una escuela que dé trámite a una vida en la que la angustia y la insatisfacción tengan cabida. Una escuela en la que podamos posibilitar la reflexión sobre otras formas de re-existir; una escuela capaz de agenciar y afirmar creativamente la vida, en la que las prácticas pedagógicas se vuelvan a afirmar como praxis con intencionalidades políticas.

\section{Referencias}

Agamben, G. (2011). ¿Qué es un dispositivo? Revista Sociológica, 26(73), 249-264.

Ahmed, S. (2015). La política cultural de las emociones. Programa Universitario de Estudios de Género de la unam.

Amaya, A. F. (2019). Emociones políticas, dispositivos escolares y discursos educativos en tiempos de seguridad democrática (20022010) [tesis de maestría]. Pontificia Universidad Javeriana, Bogotá, Colombia.

Amaya, A. F. y Torres, L. (2015). Aproximaciones entre la enseñanza de la historia presente y las pedagogías de la memoria en el escenario educativo colombiano para la paz. Ciudad paz-ando, 8(1), 142-162.

Angenot, M. (2010). El discurso social. Los límites históricos de lo pensable y lo decible. Buenos Aires: Siglo xxı. 
Atehortúa, A. (2007). Las banderas del presidente Uribe. Estado comunitario, seguridad democrática, revolución educativa. La Carreta Editores.

Beltrán, W. M. (2013). Del monopolio católico a la explosión pentecostal: pluralización religiosa, secularización y cambio social en Colombia. Universidad Nacional de Colombia.

Casañas, J. (2017, 28 de noviembre). María Fernanda Cabal explica su tesis: la masacre de las bananeras fue un mito histórico. El Espectador. https://www.elespectador.com/noticias/actualidad/maria-f-cabal-explica-su-tesis-la-masacre-de-las-bananeras-fue-un-mito-historico-articulo-725665

Dijk, T. A. (1999). El análisis crítico del discurso. Anthropos, 186, 23-36.

Duzán, M. J. (2014, 1. de febrero de ). Si no va a haber revolución, aquí hay que aprender a hacer reformas. Entrevista a Malcolm Deas. Revista Semana.

Fattal, A. (2018). Guerrilla Marketing. Counterinsurgency and capitalism in Colombia. The University of Chicago Press.

García Fanlo, L. (2011). ¿Qué es un dispositivo?: Foucault, Deleuze, Agamben. A Parte Rei. Revista de Filosofía, 74, 1-8.

Gaviria, J. O. (2005). Sofismas del terrorismo en Colombia. Planeta.

Jaramillo, J. (2014). Pasados y presentes de la violencia en Colombia. Estudio sobre las comisiones de investigación (1958-2011). Pontificia Universidad Javeriana.

López de la Roche, F. (2014). Las fricciones del poder: Patriotismo, medios de comunicación y reorientación afectiva de los colombianos bajo Uribe Vélez. Iepri, Debate.

Martínez, J. E. (2010). La universidad productora de productores: entre biopolítica y subjetividad. Universidad de La Salle.

Martínez, J. E. (2013). El dispositivo: una grilla de análisis en la visibilización de las subjetividades. Tabula Rasa, 19, 79-99.

Merton, R. K. (2002). Teoría y estructuras sociales. Fondo de Cultura Económica.

Ministerio de Educación Nacional-MEN. (2001). Lineamientos curriculares en Ciencias Sociales. https://www.mineducacion.gov.co/1621/articles-89869_archivo_pdf.pdf

Ministerio de Educación Nacional-men. (2004). Revolución educativa 2002-2010. Acciones y lecciones.

Ministerio de Educación Nacional-men. (2004). Formar para la ciudadanía ¡sí es posible! Lo que necesitamos saber y saber hacer.

Muñoz-Onofre, D. (2015). Pensar la guerra (en Colombia) más allá de la tanatopolítica. Athenea Digital, 15(4), 80-61. http://dx.doi.org/10.5565/ rev/athenea.1591 
Pinilla, A. y Rodríguez, S. P. (2005). La pedagogía por decreto en la formación de docentes. En O. Pulido y S. Baquero, Formación de maestros, profesión y trabajo docente (pp. 164-170). Universidad Pedagógica Nacional.

Pizarro Leongómez, E. (2003). Colombia: el proyecto de seguridad democrática de Álvaro Uribe. América Latina, Hoy. Revista de Ciencias Sociales, 32, 4-17.

Plataforma Colombiana de Derechos Humanos, Democracia y Desarrollo. (2003). Riendas firmes, despeñadero social. En N. Paredes Hernández, El embrujo autoritario. Primer año de gobierno de Álvaro Uribe Vélez (pp. 7-14). Ediciones Antropos.

Restrepo, A. C. (2012, 18 de agosto). Cátedra uribista. El Espectador. https:// www.elespectador.com/noticias/politica/catedra-uribista/

Rodríguez, S. P. (2013). Memoria y olvido: Usos públicos del pasado desde la Academia Colombiana de Historia (1930-1960) [tesis de doctorado]. Universidad Nacional de Colombia, Bogotá, Colombia.

Rodríguez, S. P. (2014). Enseñanza y aprendizaje de la historia en Colombia. 1990-2011. En S. Plá, \& J. Pagès, La investigación en la enseñanza de la historia en América Latina (pp. 109-154). Universidad Pedagógica Nacional y Bonilla Artiga Editores.

Rodríguez. S. P. (2016) La "Revolución Educativa" como dispositivo de olvido del "embrujo autoritario" 2002-2010 [ponencia]. XII Congreso Iberoamericano de Historia de la Educación Latinoamericana. Medellín, Universidad de Antioquia.

Rodríguez, S. P. y Moncada, O. M. (2009). Problemáticas de la enseñanza de la historia reciente en Colombia: trabajar con la memoria en un país en guerra. Reseñas, 4, 15-65.

Salamanca, C. y Jaramillo, J. (eds). (2019). Políticas, espacios y prácticas de memoria. Disputas y tránsitos actuales en Colombia y América Latina. Pontificia Universidad Javeriana.

Santana, D. (2020). Gubernamentalidad educativa y producción de subjetividades profesionales en dos generaciones de egresados de programas de comunicación social en Bogotá, 1991-2016 [tesis de doctorado]. Pontificia Universidad Javeriana, Bogotá, Colombia.

Uprimny Yepes, R. (2005). ¿Existe o no conflicto armado en Colombia? https:// www.dejusticia.org/existe-o-no-conflicto-armado-en-colombia/

Uribe Vélez, Á. (2002). Estado comunitario. http://www.alvarouribevelez. com.co/es/content/estado-comunitario

Uribe Vélez, Á. (2002). Discurso de posesión. http://www.alvarouribevelez.com.co/es 